brought about. The hot-water bath, on the other hand, is usually regarded with dread, and persons who are advised to take a warm bath are commonly enjoined with the greatest earnestness not to allow the attendant to have the water in the bath at a higher temperature than $98^{\circ}$ or $100^{\circ} \mathrm{F}$. It is no doubt a wise precaution to warn those who are the subjects of serious cardiac disease or of any profound circulatory derangement to guard against too hot a bath or too long a continuance in a bath of any kind whatever; and we caution such persons with equal earnestness against anything that may put a great or sudden strain upon the heart or arterial system. In such cases we prohibit football, and running to catch a train, an omnibus, or a tramcar; but it does not follow that people whose vascular systems are ordinarily sound may not indulge in these pleasures, if pleasures they are, to their heart's content; while to a great many of those whose muscles become weak and flabby from want of use, a good deal more running and jumping than they usually get would be beneficial in the highest degree. In the same way, it has appeared to me that persons suffering from various disorders, always excepting those above mentioned, may take the hot bath without danger, and in many cases with great advantage to themselves. By the hot bath I mean, in the case of the wet bath, one at a temperature ranging from $100^{\circ}$ to $110^{\circ}$ Fahrenheit. In the dryair bath a temperature much higher than this can of course be borne.

Some time ago an opportunity was afforded me of making some observations on the effect of the hot bath in removing some morbid conditions of the system. A man of middle life, in temperament nervous-sanguine, spare, and some what below the average height and weight, complained. of languor, debility, want of energy, and lowness of spirits. On examination it was found that his heart and arteries were sound, though his circulation was rather weak. His alimentary system was fairly good, though the quantity of food taken was below the average. His skin was somewhat dry, and a few spots of psoriasis were found on the extensor aspects of the legs, arms, and trunk. His urine was cloudy with phosphates, and below the average in quantity. As the Turkish bath was not in this case available, he was advised to take a water bath at a temperature of $105^{\circ} \mathrm{F}$, and directions were given him how to proceed in case of faintness. The cay after taking the bath his condition was wonderfully improved. His circulation was stronger, his urine was clear, and he now felt cheerful and well. This improved state of matters continued for about twelve days, when all the unpleasant symptoms reappeared, and he began to feel as ill and dejected as ever. The most natural proceeding was, of course, to order him another bath, and this he took with the same happy result as before. Since that time he has had the bot bath about once a fortnight, and by this means has managed to keep himself in very tolerable health and spirits.

It would be interesting to know the exact means by which the hot bath produces this powerful and beneficial effect on the system. It must, in the first place, be carefully borne in mind that the warm bath at a temperature below $100^{\circ} \mathrm{F}$ has no influence that can be compared with the results to be obtained from the hot bath. The hot bath stimulates the whole system, and the effect of this stimulation appears to last for some time, for the patient above referred to remained well for about a fortnight after taking the bath. Having ascertained that his diet was as nearly uniform as possible, the quantity of urea excreted on three successive days immediately before and after the bath was estimated by Russell and West's method, with the following result:-

Average quantity of urine in twonty-four hours for three days before the bath ... $91667 \mathrm{cc}$

Average weight of urea in twenty-four hours for three days before the bath ... 22 ' $8 \mathrm{grms}$.

Average quantity of urine in twenty-four nours for three days after the bath

$\Lambda$ verage weight of urea in twenty-four 26.25 grms.

From this it appears that the quantity of urine and the weight of urea excreted were below what are usually stated to be the averages for a healthy man, but that both were very perceptibly increased by the hot bath. If we may assume that the other secretions and excretions were proportionally increased, then we have clear evidence as to the proximate cause of the improvement brought $a b$ ut in the general condition of the body. Perhaps we may compare the action of the hot bath with the action of any other irritant of moderate severity. The theory of counter-irritation is confessedly somewhat hazy and inadequate; but it is a matter of every-day observation that a moderate stimulation of the skin relieves congestion of internal organs immediately subjacent to the area of stimulation. In many cases there is only a remote connexion between the vascular supply of the viscera so acted upon and the portion of skin stimulated. It must be by a reflex action of the nervous system that a poultice over the loins can relieve congestion of the kidneys, or one on the skin of the chest can benefit a similar condition in the lungs. It is not unreasonable to suppose that there is some sort of connexion between the centres presiding over the vascular supply of any portion of the body surface and those regulating similarly the quantity of blood proceeding to the organs lying immediately beneath. Thus a stimulus applied to any portion of the skin would lead to an increased activity of the nerve centre presiding over this area of the body surface, and so relieve any existing congestion of the connected or contiguous centre governing the vascular supply of the viscera lying in the neighbourhood of the stimulated surface. I think it was Dr. Berry Hart, of Edinburgh, who first suggested this explanation of the action of counter-irritants. In this way, then, the hot bath would relieve congestion of many centres and by restoring them to a healthy action would promoto the circulation of healthy blood not only through the thoracic and abdominal organs, but also through the higher nerve centres, thereby leading to the dispersion of those morbid feelings conjured up by the faulty nutrition of the cerebral convolutions. Whether this be really the mechanism by which the good effects described above are produced, on whether some other explanation can be given, it seems clear enough that the hot-water bath might be used, with proper precautions, in many cases difficult to treat in any other way, such as chronic gastric catarrh and the protean forms of dyspepsia. One of the most marked effects of the hot bath is seen in the increased force of the circulation, and following necessarily from this an increased degree of mus cular energy, with a corresponding increase of activity in the mental functions. In short, the flagging energies are restored and a more healthy tone is given to the whole system.

As in most other remedies, so in the case of the hot bath, the time and manner of application are of some importance. Like all other baths, the hot bath should be taken beforo the principal meal of the day, and if this meal be taken early the good results will be more certain than if it be taken late. The duration of the bath should be about fifteen minutes, and the temperature should be about $105^{\circ} \mathrm{F}$. If faintness should come on while in the bath, the whole head should be immersed in the hot water, and kept there for a few seconds, when the faintness will disappear. The usual directions given in public baths are to get out of the bath as soon as drowsiness or faintness begins and to ring for the attendant; but anyone who attempts to do this will most certainly aggravate his danger. As pointed out some time ago by Mr. Benham and subsequently by myself, the application of heat to the head is a potent means of averting syncope. From time to time we hear of deaths in the warm bath; and I am convinced that many of these might have been prevented by the adoption of the simple method referred to, instead of the deadly and often impossible means commonly recommended. Birmingham.

\section{PAROTITIS FOLLOWING OVARIOTOMY.}

BY W. H. JALLAND, F.R.C.S.,

SURGEON TO THE YORK COUNTY HOSPITAL.

DURING the month of January last there were some letters in THE LANCET upon the connexion between the parotid gland and the genital organs, more especially with reference to operations on the latter being followed by inflammation of the former. Mr. Stephen Paget, in his letter published on Jan. 9th, quotes five cases of parotitis following ovariotomy published by Professor Möricke, and one other case which occurred at St. Bartholomew's Hospital. As this seems a comparatively rare occurrence, I enclose th notes of the following case, which was under my care in the York County Hospital. The patient was admitted on Sept. 
17th, 1885, and was not operated on until the 21st of the following month. During the whole of the time she wns in the hospital no case of mumps occurred, nor, as far as we could gather, were there any mumps amongst the friends or in the family of any of the friends that came to visit her, so I think we may fairly assume that she did not contract this disease from an external source. The notes of the case were taken by Mr. E. F. Morris, house-surgeon.

Mary $\mathrm{P}-$, aged twenty-one, servant, was admitted into the York County Hospital on Sept. 17th, 1885. She gives the following history. About three years ago she felt very weak-much more so than she had done for some years previously. She consulted a medical man, who treated her for weakness and pain in her left side of a sharp shooting nature, situated over the tenth and eleventh ribs. This continued for a year without any other signs or symptoms, when $\operatorname{she}$ noticed that her body was enlarged (then about half its present size); it had slowly increased. The only symptoms she now complained of were weakness, headache, and pain in her left side and legs. Bowels rather costive. She commenced to menstruate at the age of fourteen; this continued normally for three or four months, then stopped again for more than a year. Since then she has been very irregular, sometimes going for two or three months, sometimes only a fortnight.

On examination, the chest \&c. appeared normal, but a distinct trace of albumen was found in the urine. Nothing else was noticed except an abnormal abdomen. The family history was good. She had been quite well up to fourteen years of age.

On examination of the abdomen, it was found to be distinctly enlarged, and, as it were, by two bodies : one, more or less round, filling up the right pelvis and reaching to the umbilicus; another, seemingly more oblong, passing up into the left flank. On palpation the swelling was more or less felt. Both bodies were regular, and in no way nodular. No other bodies could be felt; no wave, fluctuation, or thrill could be obtained. On percussion, there was dulness over the centre of the tumour extending immediately down to the pubes; resonance in both flanks, but much more marked in the right, the left being comparatively dull. The umbilicus in no way protruded. Per vaginam, the uterus was normal in position and length; os virginal; distinct movement in front of the uterus on movement of the abdominal swelling; otherwise the parts were normal. Measurement above umbilicus, $32 \frac{1}{2}$ in.; below, 36 in.

Oct. 21st: To-day, under ether, Mr. Jalland performed ovariotomy. Abdominal wall very adipose, but hæmorrhage very slight. On opening the peritoneum the tumour was found to be cystic and non-adherent. It was tapped and some fluid drawn off, when it was seen to be polycystic. With some little difficulty the growth was lifted out of the abdomen and removed. The pedicle, which was not a very broad one, was tied in two pieces with Chinese silk. The other ovary was also found to be slightly cystic, and was likewise removed. The abdomen was then wiped out with sponges, as there was some ascitic fluid in the pelvis. The abdominal wall was then stitched up with wire and catgut, and the wound dressed antiseptically. The spray was used prior to, but not during, the operation.-21st: At 6.30 P.M. the patient had well recovered from the ether, the vomiting being very slight immediately after operation. Temperature $99^{\circ}$; pulse 108. Ice was given. - 22nd: Patient easy and well. No pain. Temperature $986^{\circ}$; pulse 96 . Diet of milk, lime, and ice, in teaspoonfuls. At 8.20 P.M. the temperature, was $100 \cdot 8^{\circ}$.-23rd: At 10 A.M. there was some slight vomiting; otherwise well. Temperature $100^{\circ} 2^{\circ},-24$ th : This morning the patient complained of some stiffness of the neck, with pain at the angle of the right jaw. There is now slight swelling over the right parotid gland, which is very tender. In the evening the swelling and pain had increased.25th: At 3 A.M. the patient was in very great pain; right side of face immensely swollen. Temperature $103^{\circ}$; poultices ordered. The patient had passed an uneasy night; slept but little; pain very severe; swelling increasing. Three leeches ordered. At 6 P.M. the patient was better, the swelling less, and the pain not so great. Temperature $101^{\circ}$.26th: Swelling disappearing; pain less; feels better; no abdominal symptoms. Temperature $99^{\circ} 2^{\circ}$; pulse 105 .28th: Right side of face painless, but still swollen.30th: Left side of face swollen and painful. Leeches ordered.-Nov. 2nd: Pain nearly all gone; both sides of face still somewhat swollen.-4th : Antiseptics left off; wound almost healed. The patient is now practically well.

\section{Aู Mttirtox}

\section{HOSPITAL PRACTICE, BRITISH AND FOREIGN.}

Nulla autem est alia pro certo noscendi via, nisi quamplurimas et morborum et dissectionum historias, tum aliorum tum proprias collectas habere, et inter so comparare.-MorgatinI De Sed. et Caus. Morb. lib. iv. Procmium.

GUY'S HOSPITAL.

CASES OF STRANGULATED HERNIA; OPERATION FOR REDUCTION AND EXCISION OF THE SAC; REMARKS.

(Under the care of Mr. R. CLEMent Locas.)

Mr. Clement Lucas has long maintained that an operation for strangulated hernia ougbt not to be considered complete until the sac has been excised, and that the aftertreatment is often unnecessarily prolonged. Formerly, it used to be considered always advisable to keep a patient lying in the hospital for a month or six weeks after kelotomy. After excising the sac, in uncomplicated cases, he completely closes the canal and the wound. Primary union is thus obtained, and the patient sits up on the sixth day, and leaves the hospital, wearing a truss, on the fourteenth day after the operation. In a paper read before the Clinical Society in October, 1885, Mr. Lucas showed how, by excising the sac and suturing the umbilical aperture, the mortality after the operation for umbilical hernia might be lessened. It will be observed in the following cases, two of which were femoral and one inguinal, complicated with undescended testicle, the patients in each case left the hospital well on the fourteenth day. It is hoped that others will more generally adopt this method of treating strangulated hernia. For the reports of the three cases, all operated upon within a week, we are indebted to Mr. Metzgar, the dresser, who attended to the patients after the operations.

CAsE 1. Strangulated Hernia in an Infant complicated with undescended Testicle; Operation for Reduction; Excision of Sac and Testicle.-W. W. C - , aged one year and eleven months, was admitted into Lydia ward on the evening of Sept. 1st, at 11 P.M., suffering from strangulated inguinal hernia on the right side. A hernia had first come down in that position when he was three months old, his mother returning it by pressure. As the testicle had not descended on that side, a truss had not been applied, but his mother had been warned of the danger and Instructed to come to the hospital immediately if the hernia became irreducible, or if at any time the testicle appeared, in order that on the descent of that organ a truss might be adjusted above it. At 3 o'clock that afternoon the child's bowels had been opened, and at 8 o'clock, whilst crying, the hernia came down, it being rather larger than it had ever been before-viz, the size of an ordinary hen's egg. His mother tried to return it as she generally did, but was unable; so he was brought to the hospital.

On admission the patient's temperature was $100 \cdot 2^{\circ}$ and the pulse 105. The hernia being very tense, an icebag was applied till 12 P.M., when he commenced to vomit for the first time. Taxis was then employed, but for a short time only, and, the hernia being unreduced, chloroform was administered. Mr. Lucas then tried taxis in the inverted position, but, owing to the tense condition of the tumour, for a short time only. An oblique incision was then made over the tumour, and the structures were severally divided down to the sac; as the hernia was not constricted externally to that structure, it was opened. Some turbid serum was let out, and it was seen that, though dull in colour, the intestines still maintained their characteristic shiny appearance. The constriction, which was at the internal ring, was then divided and the bowel returned. The testicle was found lying about three-quarters of an inch helow the internal ring; the sac containing the testicle was then separated, and, having been transfixed and tied with a double catgut ligature, was excised. The margins of the canal were then sewn up with three chromic catgut ligatures, these going deeply into the posterior wall. The skin incision having 